\title{
Left Posterior Descending Artery
}

National Cancer Institute

\section{Source}

National Cancer Institute. Left Posterior Descending Artery. NCI Thesaurus. Code C116178.

The second posterolateral branch originating from the posterior atrioventricular left circumflex artery in left dominant and mixed circulations. 